\title{
Primary central nervous system lymphoma in children
}

\author{
Oussama Abla, M.D., and Sheila Weitzman, M.B., F.C.P.(SA), F.R.C.P. \\ Division of Hematology/Oncology, The Hospital for Sick Children and Department of Paediatrics, \\ University of Toronto, Ontario, Canada
}

\begin{abstract}
$\checkmark$ Primary central nervous system lymphoma (PCNSL) is a very rare brain tumor in children, and the optimal management and prognosis of such patients have yet to be defined. In this study, the incidence rate, clinical features, diagnosis, and treatment of childhood PCNSL are reviewed. Except for human immunodeficiency virus-related PCNSL, the prognosis for patients with this tumor type is significantly better in children than in adults. In the absence of prospective studies, it is very difficult to determine the true incidence and the best therapeutic strategy for this rare entity. The majority of children with PCNSL, however, can achieve long-term remissions with intensive chemotherapy alone (an estimated 70\% 5-year event-free survival rate), and cranial irradiation can be reserved for relapse of the disease. Further progress in the management of childhood PCNSL will require prospective multinational studies.
\end{abstract}

\section{KEY WORDS • primary central nervous system lymphoma • chemotherapy • radiotherapy • children}

$\mathrm{P}$ RIMARY central nervous system lymphoma is an extranodal malignant lesion that is confined to the brain, eyes, and/or leptomeninges. Cases of PCNSL represent 4 to $7 \%$ of primary brain tumors, and its incidence has been increasing in the last three decades. ${ }^{74}$ The incidence is increased 3600 -fold in patients with AIDS. ${ }^{22}$ It can affect all age groups, with a median age in the sixth decade in patients without AIDS. ${ }^{39}$ This tumor is rare in childhood; thus, the incidence and prognosis in this age group are not well defined and the best treatment strategy remains unclear. The aims of this review are to describe the incidence rate, clinical features, therapy, and outcome of childhood PCNSL and to discuss the issues pertinent to therapeutic decision making in a young patient.

\section{Epidemiology}

Among 596 cases of PCNSL reported to the Brain Tumor Registry of Japan between 1969 and 1990, only nine pediatric cases $(1.5 \%)$ were observed ${ }^{41}$ In the US, the Surveillance, Epidemiology, and End Results program (which ran from 1973 to 1998) found 1\% of all PCNSLs in patients younger than 19 years of age, ${ }^{40}$ giving an estimated incidence of 15 to 20 cases per year in North America. It is estimated that 14 cases of pediatric PCNSL will be reported annually to the newly opened rare nonHodgkin lymphoma registry of the Children's Oncology

Abbreviations used in this paper: $\mathrm{ALCL}=$ anaplastic large cell lymphoma; AraC = cytarabine; $\mathrm{BBB}=$ blood-brain barrier; $\mathrm{CHOP}$ = cyclophosphamide, doxorubicin, Oncovin (vincristine), and prednisone; $\mathrm{CNS}=$ central nervous system; $\mathrm{CSF}=$ cerebrospinal fluid; DLBCL = diffuse large B-cell lymphoma; EBV = Epstein-Barr virus; EFS = event-free survival; MTX = methotrexate; PCNSL = primary CNS lymphoma.
Group. ${ }^{2}$ This tumor tends to occur more frequently in immunodeficient children, with an incidence of 0.57 to $1 \%$ in HIV-infected children ${ }^{61}$ and $4 \%$ in patients with congenital immunodeficiency. ${ }^{64}$ Nevertheless, most of the 43 pediatric patients with PCNSL reported during the last decade were immunocompetent. These 43 cases include 31 previously reported ones and 12 cases from our recent multiinstitutional series. ${ }^{2}$ The median age of the 43 patients was 9 years (range $2-18$ years) at diagnosis. In an earlier review, however, PCNSL was reported in infants as young as 1 month old..$^{41}$ In the present review, PCNSL was more common in male than in female patients (26 compared with 17).

\section{Clinical Presentation}

Clinical findings at presentation include increased intracranial pressure (severe headaches, vomiting, and papilledema), facial nerve palsy, diplopia, dysarthria, ataxia, bulbar palsy, quadriparesis, and obtundation. ${ }^{1,2,75,79,81}$ Less frequent findings include seizures, acute blindness, proptosis, lower- and upper-limb muscle weakness, nystagmus, paresthesias, personality change, lethargy, and somnolence. . $^{2,15,29,44,67,77,78}$ Children with PCNSL may also present solely with diabetes insipidus and progressive panhypopituitarism due to pituitary and hypothalamic involvement. ${ }^{9,17,70}$

\section{Radiographic Features}

Pediatric PCNSL may present as a solitary mass or as a multifocal tumor. The most frequent tumor locations in children are the parietal and frontal lobes, cerebellum, pituitary stalk, and hypothalamus, ${ }^{2}$ whereas PCNSL in adults most commonly involves the periventricular re- 
gion, basal ganglia, corpus callosum, and the deep white matter. ${ }^{19}$ In children with PCNSL, contrast-enhanced computed tomography scanning usually shows a characteristic heterogeneous pattern, marked edema, and a prominent mass effect with a ring-like peripheral pattern of enhancement. ${ }^{65}$ Heterogeneous and ring-like enhancement are less common in adults. ${ }^{19}$ Occasionally, pediatric cases have predominant leptomeningeal involvement and no evidence of an intracranial mass. Eight (18\%) of the 43 pediatric cases reported in the last 10 years were primary leptomeningeal lymphomas.

\section{Pathological Features}

Reports on 43 pediatric patients with PCNSL were reviewed. The diagnosis was established either by stereotactic biopsy (24 cases), leptomeningeal biopsy (two), open biopsy (three), autopsy (two), or by immunocytochemical, cytogenetic, and polymerase chain reaction analysis of CSF (nine). In the other three children the diagnostic method was not reported. The DLBCL is the most common subtype (13 [30\%] of 43), followed by ALCL (21\%; seven T-cell and two null-cell tumors), lymphoblastic lymphoma (16\%; five precursor-B and two Tcell lesions $\left.{ }^{6,78}\right)$, Burkitt (12\%), histiocytic (5\%, confirmed by immunohistochemical findings), and other (6\%) lesions. Histological findings were not reported in $10 \%$ of cases. The most common immunophenotype was mature B-cell (43\%), followed by T-cell (21\%), precursor B-cell (12\%), null-type (10\%), and histiocytic $(5 \%)$ tumors. By contrast, T-cell lymphomas comprise less than $5 \%$ of all cases of adult PCNSL, ${ }^{76}$ and to the best of our knowledge precursor B-cell lymphomas have not been reported in adults.

\section{Prognosis and Biology}

The prognosis of adult patients with PCNSL is poor, with an estimated 5-year EFS of 25 to $40 \% .^{49}$ In pediatric patients with PCNSL, however, the prognosis has improved over the last 10 years. A review by Kai, et al., ${ }^{41}$ of pediatric cases treated between 1975 and 1991 found a mean survival time of 17.1 months (range 0.3-78 months), with the majority of cases treated with cranial radiotherapy alone or combined with moderate chemotherapy. In our more recent pediatric series, the 5-year EFS was $70 \%$ in children with PCNSL who were treated with chemotherapy alone. ${ }^{2}$ The use of more intensive chemotherapy regimens based mainly on high-dose MTX and high-dose AraC may have contributed to this improvement. Young age is considered to be a favorable prognostic factor in PCNSL in adults ${ }^{13}$ which may reflect differing biology or the ability to tolerate more intensive therapy. Performance status (Karnofsky Performance Scale or Eastern Cooperative Oncology Group score) is another prognostic indicator that was not assessed in any of the pediatric studies.

A correlation between histological findings and prognosis can be inferred, with the histiocytic subtype being the most aggressive among published pediatric cases of PCNSL; the overall survival was only 3 to 4 months. ${ }^{18,77}$ Lymphoblastic lymphoma, which occurred more frequently in children, was thought to have a worse progno- sis with a high relapse rate and a tendency toward leukemic transformation. ${ }^{41}$ In the present review, however, all patients with B-lineage lymphoblastic lymphoma were alive 22 or more to 77 or more months after treatment with an intensive chemoradiotherapy combination. ${ }^{1,29,69}$ Among the children in whom an ALCL was diagnosed, a better outcome was associated with ALK-1 positivity, lack of necrosis, and unifocal tumor. ${ }^{35}$ Within the most common subtype of DLBCL, studies in adults have demonstrated the prognostic importance of the germinal center stage of systemic DLBCL. ${ }^{23}$ Coupland, et al., ${ }^{23}$ showed that most PCNSLs in adults were late germinal center or postgerminal center stage, and Braaten, et al., ${ }^{14}$ demonstrated a median survival duration of 101 months for those with $B C L-6$ expression (reflecting the germinal center stage) compared with 14.7 months in patients whose tumors were $B C L-6$-negative. In pediatric cases of DLBCL, most tumors have been shown to be late germinal center stage. ${ }^{60}$ If this is true for pediatric cases of PCNSL as well, it may, at least in part, explain the better prognosis in children.

\section{Treatment}

The best treatment strategy for pediatric PCNSL has yet to be established, although many reports have shown long-term survival with chemotherapy alone without cranial radiotherapy. 2,21,38,75,82 Possibilities for therapy include surgery, cranial radiotherapy alone, chemotherapy followed by cranial radiotherapy, chemotherapy alone, BBB disruption-enhanced chemotherapy, high-dose chemotherapy with stem cell rescue, and various new experimental therapies. All authors agree that cranial radiotherapy prior to chemotherapy significantly increases neurotoxicity, and therefore it is not recommended.

\section{Surgery Alone}

Because the overall survival after surgery alone is 3 to 5 months,,$^{51}$ the utility of surgery in both pediatric and adult patients with PCNSL is limited to biopsy sampling. Aggressive surgery has been shown to worsen the neurological deficit with no increase in the survival rate. As a result, the recommended approach to diagnosis is CSF examination when safe, followed by a stereotactic biopsy procedure if the CSF findings are negative.

\section{Cranial Radiotherapy Alone}

Due to the extreme radiosensitivity of this tumor, cranial radiotherapy has been the mainstay of treatment for PCNSL for many years, ${ }^{52}$ with doses ranging from 36 to 45 Gy. Earlier studies demonstrated a $90 \%$ response rate to cranial radiotherapy alone, with a median survival duration of 11.6 to 18 months; a 5-year overall survival rate of $4 \%$; a high relapse rate (80\%) over 10 to 14 months; and severe neurotoxicity, particularly in elderly adults. ${ }^{12}$ In the study of cranial radiotherapy alone published by Nelson, et al., ${ }^{53} 61 \%$ of patients suffered a relapse of the tumor within the radiation field. Among the pediatric cases reported in the last decade, three were treated with cranial radiotherapy alone: two patients were alive at 56 and 60 months, respectively, and the third suffered a relapse at 12 months. ${ }^{19,35,41}$ The numbers are too small for meaningful 
assessment of treatment efficacy, but in children there are even greater concerns about the use of cranial radiotherapy due to the high risk of secondary brain tumors ${ }^{48}$ as well as the risk of severe neurocognitive dysfunction. ${ }^{62}$ Treatment of pediatric PCNSLs with cranial radiotherapy alone is therefore not indicated, except in the palliative setting.

\section{Chemotherapy Followed by Cranial Radiotherapy}

Early attempts to improve the survival rate by adding standard chemotherapy such as CHOP to cranial radiotherapy failed, probably due to the inability of component drugs such as vincristine and doxorubicin to cross the $\mathrm{BBB}^{50}$ The combination of high-dose MTX and cranial radiotherapy resulted in better survival rates (30-60 months) but worse neurotoxicity in adult patients. ${ }^{3}$ Twelve children of the 43 in this review received chemoradiotherapy; eight $(66 \%)$ of the 12 were alive at the time of this report (22-98 months after diagnosis). Chemotherapy regimens were mostly based on high-dose MTX and highdose $\mathrm{AraC}$ combined with dexamethasone or prednisone, plus or minus other drugs. Radiotherapy consisted of either cranial radiotherapy or craniospinal radiotherapy, with doses ranging from 12 to $50 \mathrm{~Gy}$. No long-term late effect data are available in this group of patients.

\section{Chemotherapy Alone}

A number of studies conducted in adult patients support the suggestion that when drugs that cross the BBB are used, patient survival is equivalent to that seen after combined therapy, with significantly fewer cognitive defects. ${ }^{33,34,59,63}$ Based on results of the largest single case series of pediatric PCNSL, consisting of 12 patients, we would suggest that most children with PCNSL can achieve long-term remissions with chemotherapy alone and without cranial radiotherapy. ${ }^{2}$ Ten children underwent first-line treatment with chemotherapy alone (mostly high-dose MTX and high-dose AraC combinations), with a 5-year EFS of $70 \%$ and a median follow-up time of 79 months (range 31-122 months). Two children received chemotherapy and cranial radiotherapy, one of whom experienced a relapse and died of his disease, whereas the other remains in continuous complete remission more than 98 months from diagnosis.

These results are concordant with the international FAB LMB-96 study results in children and adolescents with CNS-positive B-cell non-Hodgkin lymphoma, in whom the abandonment of cranial irradiation and an additional course of systemic high-dose MTX $\left(8 \mathrm{~g} / \mathrm{m}^{2}\right)$ and intrathecal chemotherapy resulted in a $70 \%$-year EFS rate. ${ }^{36}$ Among the total group of 43 pediatric patients with PCNSL, 23 were treated with chemotherapy alone; 18 $(78 \%)$ of the 23 were alive at the time of this report. It is noteworthy that two of the patients who experienced a relapse without prior radiation therapy underwent salvage treatment with autologous stem cell transplant combined with cranial radiotherapy in one, ${ }^{2}$ and EBV-cytotoxic immunotherapy followed by allogeneic stem cell transplant ${ }^{81}$ in the other.

High-dose MTX is the single most important drug for the treatment of PCNSL. ${ }^{5}$ It has been established that MTX has a lymphoblastolytic action and the ability to penetrate the CNS at doses of $1 \mathrm{~g} / \mathrm{m}^{2}$ or more. ${ }^{49}$ At doses of $3.5 \mathrm{~g} / \mathrm{m}^{2}$ or more it yields tumoricidal levels in the CSF. ${ }^{10}$ The optimal dose of MTX in PCNSL is not well defined, although in most trials investigators used doses ranging from 1 to $5 \mathrm{~g} / \mathrm{m}^{2}$, with $3.5 \mathrm{~g} / \mathrm{m}^{2}$ being the most common dose. ${ }^{30}$ Intensifying the MTX dose to $8 \mathrm{~g} / \mathrm{m}^{2}$, an amount commonly used in pediatric systemic non-Hodgkin lymphoma, was found to be beneficial in one study. ${ }^{80} \mathrm{High}$ dose MTX produces a response rate of 52 to $88 \%$ when given as a single agent and 70 to $94 \%$ when administered with other drugs and cranial radiotherapy. ${ }^{24}$ However, single-agent therapy, even with very-high-dose MTX (8 g/ $\mathrm{m}^{2}$ ) leads to a higher risk of relapse, at least in adult patients. ${ }^{12}$ In agreement with this, one HIV-positive child with PCNSL, who was treated with high-dose MTX monotherapy, suffered a relapse and died 4 months after diagnosis. $^{2}$

Cytarabine also has a proven efficacy in PCNSL, especially at doses of $3 \mathrm{~g} / \mathrm{m}^{2}$ or more. ${ }^{71}$ Adding high-dose AraC to high-dose MTX has given better overall survival rates compared with high-dose MTX alone (2-year overall survival $64 \%$ compared with $18 \%$ ). ${ }^{31}$ The combination of MTX and AraC at high doses has a synergistic action. ${ }^{32}$ Pels, et al. ${ }^{59}$ have shown a benefit from the combination of high-dose MTX $\left(5 \mathrm{~g} / \mathrm{m}^{2}\right)$ and high-dose $\operatorname{AraC}\left(3 \mathrm{~g} / \mathrm{m}^{2}\right)$ in one prospective study performed in adults. Furthermore, the LMB and Berlin-Frankfurt-Münster studies have confirmed a benefit from the introduction of highdose AraC (CYVE protocol) together with an increased dose of MTX $\left(8 \mathrm{~g} / \mathrm{m}^{2}\right)$ in CNS-positive childhood systemic B-cell lymphomas. ${ }^{57}$ In our review, 16 children with PCNSL who received high-dose AraC combined with other agents had long-term remissions.

\section{Other Chemotherapeutic Agents}

Drugs with poor BBB penetration, such as $\mathrm{CHOP}$, are very active against systemic non-Hodgkin lymphoma but have little role in the treatment of PCNSL. Four trials have failed to show any benefit of CHOP plus cranial radiotherapy compared with cranial radiotherapy alone. ${ }^{46,66,68,73}$ Furthermore, these agents usually cause significant myelosuppression, peripheral neuropathy, and potential cardiomyopathy. Etoposide and ifosfamide have a good CNS penetration and were used in combination with $\mathrm{AraC}$ as salvage chemotherapy in recurrent PCNSL, with a 1-year overall survival rate of $41 \%{ }^{8}$ Etoposide is also given in the intensification phase of the LMB-89 protocol, a therapy that was used successfully in some pediatric PCNSL cases (Table 1) ${ }^{58}$ High-dose busulfan, cyclophosphamide, and thiotepa have good CNS penetration. Studies in adults have shown superiority of this combination as conditioning therapy for stem cell transplant in refractory PCNSL. ${ }^{72}$

\section{Blood-Brain Barrier Disruption}

The normal BBB prevents passage of ionized water-soluble substances with molecular weights more than 180 , and most chemotherapy drugs have a molecular weight between 200 and 1200. Even if the BBB is disrupted by the tumor, the disruption is variable and dependent on tumor type. In addition, most investigators agree that dose intensity is a significant predictor of longer survival time in PCNSL. ${ }^{45}$ With these points in mind, Neuwelt, et al., ${ }^{55}$ 
TABLE 1

Literature review of pediatric PCNSL cases reported between 1996 and 2006*

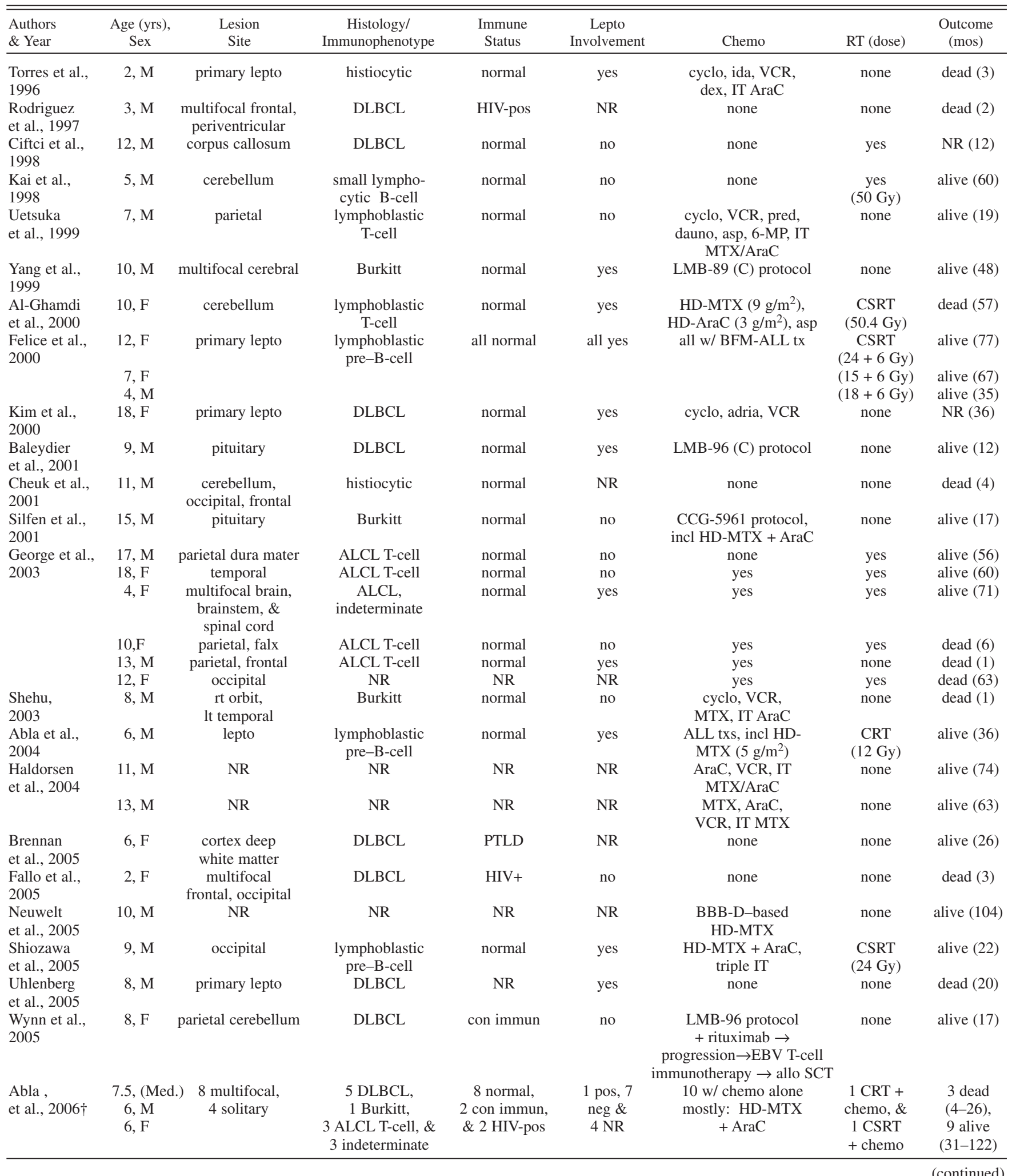


Primary central nervous system lymphoma in children

TABLE 1 (continued)

Literature review of pediatric PCNSL cases reported between 1996 and 2006*

\begin{tabular}{|c|c|c|c|c|c|c|c|c|}
\hline $\begin{array}{l}\text { Authors } \\
\& \text { Year }\end{array}$ & $\begin{array}{l}\text { Age (yrs), } \\
\text { Sex }\end{array}$ & $\begin{array}{l}\text { Lesion } \\
\text { Site }\end{array}$ & $\begin{array}{c}\text { Histology/ } \\
\text { Immunophenotype }\end{array}$ & $\begin{array}{l}\text { Immune } \\
\text { Status }\end{array}$ & $\begin{array}{c}\text { Lepto } \\
\text { Involvement }\end{array}$ & Chemo & RT (dose) & $\begin{array}{l}\text { Outcome } \\
\text { (mos) }\end{array}$ \\
\hline $\begin{array}{l}\text { Taga et al., } \\
2006\end{array}$ & $11, \mathrm{M}$ & primary lepto & Burkitt & normal & yes & $\begin{array}{l}\text { BFM-90 protocol for NHL, } \\
\text { incl HD-MTX }\left(5 \mathrm{~g} / \mathrm{m}^{2}\right)+ \\
\text { HD-AraC }\left(2 \mathrm{~g} / \mathrm{m}^{2}\right)+\text { triple IT }\end{array}$ & none & alive (33) \\
\hline
\end{tabular}

*Adria = adriamycin; ALL = acute lymphoblastic leukemia; allo SCT = allogeneic stem cell transplant; asp = asparaginase; $\mathrm{BBB}-\mathrm{D}=\mathrm{BBB}$ disruption; $\mathrm{BFM}=$ Berlin-Frankfurt-Munster; chemo = chemotherapy; con immun = congenital immunodeficiency; CRT = cranial radiation therapy; CSRT = craniospinal RT; cyclo = cyclophosphamide; dauno = daunomycin; dex = dexamethasone; HD = high-dose; ida = idarubicin; incl = including; IT = intrathecal; lepto = leptomeningeal; Med = median; 6-MP = 6-mercaptopurine; neg = negative; NHL = non-Hodgkin lymphoma; NR = not reported; pos = positive; pre$\mathrm{B}=$ precursor $\mathrm{B}$; pred = prednisone; $\mathrm{PTLD}=$ posttransplant lymphoproliferative disorder; $\mathrm{tx}=$ therapy; VCR $=$ vincristine.

$\dagger$ This series includes the patient reported by Capra, et al.

to cause BBB disruption, therefore enhancing chemotherapy delivery to microscopic tumoral areas.

To date, more than 3000 procedures have been performed in more than 300 adult patients by the BBB Disruption Consortium. In one such study, intraarterial MTX ( $2.5 \mathrm{~g} /$ day, 2 days) in conjunction with BBB disruption and without cranial radiotherapy gave an estimated 5-year survival rate of $42 \%$ when used as first-line therapy, without causing cognitive impairment. ${ }^{49}$ No survivors were seen among patients in whom previous cranial radiotherapy had failed. These results were believed to be equal to those of non-CNS lymphoma in adults, but they are nonetheless significantly inferior to the results found in pediatric patients treated with systemic chemotherapy alone.

One of the pediatric patients with PCNSL whose case was reviewed was treated with $\mathrm{BBB}$ disruption-enhanced MTX chemotherapy and remains well at 104 months with no cognitive dysfunction. ${ }^{54}$ However, there is no evidence that $\mathrm{BBB}$ disruption is superior to high-dose systemic MTX therapy, at least in children, and the toxicities associated with BBB disruption, such as seizures (6.8\%), strokes (6-8\%), nonfatal thromboembolic events (23\%), dissections, and edema ${ }^{45}$ cannot be justified in this population, at least with the present state of knowledge. Finally, $\mathrm{BBB}$ disruption is a very complex procedure and its use is limited to centers with a specialized team. The BBB disruption-enhanced therapy may be useful in patients who cannot tolerate high systemic doses, in pediatric salvage protocols, or as a means to administer other therapies such as monoclonal antibodies or gene therapies that do not cross the BBB.

\section{Role of Intrathecal Chemotherapy}

In children with parenchymal PCNSL, lymphoma cells were detected in the CSF in seven (16\%) of 43 cases at diagnosis, and primary leptomeningeal lymphoma without parenchymal CNS disease was identified in eight $(18 \%)$ of 43 . Primary leptomeningeal lymphoma represents $7 \%$ of PCNSL cases in adults and usually has a very poor prognosis, with a median survival duration of 8 months ${ }^{47}$ However, five of eight of the pediatric patients with primary leptomeningeal lymphoma are long-term survivors. Intrathecal chemotherapy is the mainstay of therapy for lymphomatous meningitis; however, the role of both intraventricular and intrathecal therapy is still controversial, especially when high doses of intravenous MTX $\left(>3 \mathrm{~g} / \mathrm{m}^{2}\right)$ are used. ${ }^{43}$ The major problem is the additional neurotoxicity associated with intrathecal MTX, particularly when given in conjunction with systemic MTX or cranial radiotherapy. Of the 43 pediatric patients, 26 received intrathecal chemotherapy. Due to the retrospective nature of this review and because of the heterogeneity of treatment strategies, the impact of intrathecal chemotherapy on the outcome in children with PCNSL cannot be truly assessed. In the absence of prospective studies, we suggest reserving intrathecal chemotherapy for CSF-positive patients.

\section{Stem Cell Transplant}

Following the study by Soussain, et al. ${ }^{72}$ in which a 3year EFS of 53\% and an overall survival of $63 \%$ were demonstrated in 22 patients with relapses of PCNSL who received high-dose chemotherapy and autologous stem cell transplant, a number of studies were performed in which investigators looked at the role of autologous stem cell transplant as front-line therapy for PCNSL, with survival durations ranging from 50 to $69 \%$ at 5 years. ${ }^{4,16}$ Two pediatric patients with PCNSL in this series underwent autologous stem cell transplant. One patient received the transplant as part of her front-line therapy and remains in continuous complete remission at more than 91 months from diagnosis; the second underwent an autologous stem cell transplant combined with cranial radiotherapy after relapse and is in continuous complete remission at more than 55 months. ${ }^{2}$ The patient who underwent allogeneic stem cell transplant after progressive disease is alive at 17 months. ${ }^{81}$ The role of stem cell transplant as first-line treatment in pediatric PCNSL is still unclear. However, high-dose therapy with rescue seems a reasonable alternative for slowly responding or refractory disease. Due to the high incidence of neurotoxicity, stem cell transplant may not be feasible in patients who have received previous radiation therapy. 5,72

\section{Treatment of Immunocompromised Children}

Eight of 43 pediatric patients with PCNSL in this review were immunodeficient. One patient with EBV-positive CNS posttransplant lymphoproliferative disorder remains in continuous complete remission at more than 26 months after withdrawal of immunosuppression and intravenous acyclovir. ${ }^{15}$ In four children, HIV-related PCNSL was diagnosed in this review; two were not treated, ${ }^{28,61}$ whereas the other two were treated with monochemotherapy (one with high-dose MTX and the other with hydroxyurea). ${ }^{2}$ All four patients died between 2 and 26 months after their diagnosis. All 10 pediatric patients with HIV- 
associated PCNSL reported on since 1986 have died. ${ }^{720,25-28,37,42,61}$ Highly active antiretroviral therapy combined with cranial radiotherapy ( $\geq 30 \mathrm{~Gy}$ ) improved survival duration for adults with HIV and PCNSL. ${ }^{56}$ Because the outcome in these patients is further compromised by coexisting AIDS-related encephalopathy, ${ }^{37}$ however, this therapy cannot be recommended for pediatric patients with HIV, and cranial irradiation should be reserved for palliation..$^{37}$ The utility of highly active antiretroviral therapy and effective multidrug chemotherapy in pediatric HIV-associated PCNSL is unknown. By contrast, three patients with congenital immunodeficiencies and PCNSL are in continuous complete remission at more than 17, 90, and 122 months from initial diagnosis, following treatment with multiagent chemotherapy protocols. ${ }^{2,81}$

\section{Conclusions}

The literature on PCNSL in children is scant and sporadic due to the rarity of this disease. It is very difficult to determine the true incidence of pediatric PCNSL, and it is likely that many cases of this lesion are not being reported. Firm conclusions regarding the best therapeutic options are difficult in the absence of prospective studies. With the exception of HIV-associated PCNSL, review of the published pediatric cases supports the suggestion that the prognosis is significantly better in patients who present with PCNSL in childhood than in their adult counterparts. Whether this difference is due to different biology or better tolerance of chemotherapy is uncertain, but based on our review of the existing literature we suggest that the majority of pediatric patients can be cured with high-dose multidrug chemotherapy and that cranial irradiation can be reserved for refractory or recurrent disease. Intrathecal therapy can be reserved for patients with lymphomatous meningitis, and the role of BBB disruption and ultrahighdose therapy and stem cell rescue remain to be elucidated. Due to the rarity of the condition, multinational cooperative trials are essential for progress to be made.

\section{References}

1. Abla O, Naqvi A, Ye C, Bhattacharjee R, Shago M, Abdelhaleem $\mathrm{M}$, et al: Leptomeningeal precursor B-cell lymphoblastic lymphoma in a child with minimal bone marrow involvement. J Pediatr Hematol Oncol 26:469-472, 2004

2. Abla O, Sandlund JT, Sung L, Brock P, Corbett R, Kirov I, et al: A case series of pediatric primary central nervous system lymphoma: favorable outcome without cranial irradiation. Ped Blood Cancer 47:880-885, 2006

3. Abrey LE, DeAngelis LM, Yahalom J: Long-term survival in primary CNS lymphoma. J Clin Oncol 16:859-863, 1998

4. Abrey LE, Moskowitz CH, Mason WP, Crump M, Stewart D, Forsyth P, et al: Intensive methotrexate and cytarabine followed by high-dose chemotherapy with autologous stem-cell rescue in patients with newly diagnosed primary CNS lymphoma: an intent-to-treat analysis. J Clin Oncol 21:4151-4156, 2003

5. Abrey LE, Yahalom J, DeAngelis LM: Treatment for primary CNS lymphoma: the next step. J Clin Oncol 18:3144-3150, 2000

6. Al-Ghamdi H, Sabbah R, Martin J, Patay Z: Primary T-cell lymphoma of the brain in children: a case report and literature review. Ped Hematol Oncol 17:341-343, 2000

7. Anderson DW, Macher AM, Shanks D, Birx D, Pezeshkpour G, Parisi J, et al: Case for diagnosis. AIDS. Milit Med 152: M33-
M40, 1987

8. Arellano-Rodrigo E, Lopez-Guillermo A, Bessell EM, Nomdedeu B, Montserrat E, Graus F, et al: Salvage treatment with etoposide (VP-16), ifosfamide and cytarabine (Ara-C) for patients with recurrent primary central nervous system lymphoma. Eur J Haematol 70:219-224, 2003

9. Baleydier F, Galambrun C, Manel AM, Guibaud L, Nicolino M, Bertrand Y: Primary lymphoma of the pituitary stalk in an immunocompetent 9-year-old child. Med Pediatr Oncol 36: 392-395, 2001

10. Balis FM, Poplack DG: Central nervous system pharmacology of antileukemic drugs. Am J Pediatr Hematol Oncol 11: 74-86, 1989

11. Bessell EM, Graus F, Lopez-Guillermo A, Lewis SA, Villa S, Verger E, et al: Primary non-Hodgkin's lymphoma of the CNS treated with $\mathrm{CHOD} / \mathrm{BVAM}$ or BVAM chemotherapy before radiotherapy: long-term survival and prognostic factors. Int J Radiat Oncol Biol Phys 59:501-508, 2004

12. Bessell EM, Lopez-Guillermo A, Villa S, Verger E, Nomdedeu B, Petit J, et al: Importance of radiotherapy in the outcome of patients with primary CNS lymphoma: an analysis of the CHOD/BVAM regimen followed by two different radiotherapy treatments. J Clin Oncol 20:231-236, 2002

13. Blay JY, Ongolo-Zogo P, Sebban C, Carrie C, Thiesse P, Biron $\mathrm{P}$ : Primary cerebral lymphomas: unsolved issues regarding first line treatment, follow-up, late neurological toxicity and treatment of relapses. Ann Oncol 11:39-44, 2000

14. Braaten KM, Betensky RA, de Leval L, Okada Y, Hochberg FH, Louis DN, et al: BCL6 expression predicts improved survival in patients with primary central nervous system lymphoma. Clin Cancer Res 9:1063-1069, 2003

15. Brennan KC, Lowe LH, Yeaney GA: Pediatric central nervous system posttransplant lymphoproliferative disorder. AJNR Am J Neuroradiol 26:1695-1697, 2005

16. Brevet M, Garidi R, Gruson B, Royer B, Vaida I, Damaj G, et al: First-line autologous stem cell transplantation in primary CNS lymphoma. Eur J Haematol 75:288-292, 2005

17. Capra M, Wherrett D, Weitzman S, Dirks P, Hawkins C, Bouffet E: Pituitary stalk thickening and primary central nervous system lymphoma. J Neurooncol 67:227-231, 2004

18. Cheuk W, Walford N, Lou J, Lee AKC, Fung CF, Au KH, et al: Primary histiocytic lymphoma of the central nervous system: a neoplasm frequently overshadowed by a prominent inflammatory component. Am J Surg Pathol 25:1372-1379, 2001

19. Ciftci E, Erden I, Akyar S: MR findings of primary central nervous system lymphoma in a child. Acta Radiol 39:727-729, 1998

20. Cocchi P, Calabri G, Salvi G, Nieri R, DeMartino M, DiLollo S: AIDS-associated CNS lymphoma of the brain in a child. Pediatrics 82:678, 1988

21. Cohen IJ, Vogel R, Matz S, Weitz R, Mor C, Stern S, et al: Successful non-neurotoxic therapy (without radiation) of a multifocal primary brain lymphoma with a methotrexate, vincristine and BCNU protocol (DEMOB). Cancer 57:6-11, 1986

22. Cote TR, Manns A, Hardy CR, Yellin FJ, Hartge P: Epidemiology of brain lymphoma among people with or without acquired immunodeficiency syndrome. AIDS/Cancer Study Group. J Natl Cancer Inst 88:675-679, 1996

23. Coupland SE, Loddenkemper C, Smith JR, Braziel RM, Charlotte F, Anagnostopoulos I, et al: Expression of immunoglobulin transcription factors in primary intraocular lymphoma and primary central nervous system lymphoma. Invest Ophthalmol Vis Sci 46:3957-3964, 2005

24. DeAngelis LM, Seiferheld W, Schold SC, Fisher B, Schultz CJ: Combination chemotherapy and radiotherapy for primary central nervous system lymphoma: Radiation Therapy Oncology Group Study 93-10. J Clin Oncol 20:4643-4648, 2002

25. Del Mistro A, Laverda A, Calabrese F, DeMartino M, Calabri G, Cogo P, et al: Primary lymphoma of the central nervous sys- 
tem in two children with acquired immune deficiency syndrome. Am J Clin Pathol 94:722-728, 1990

26. Dickson DW, Belman AL, Park YD, Wiley C, Horoupian DS, Llena J, et al: Central nervous system pathology in pediatric AIDS: an autopsy study. APMIS 8:40-57, 1989

27. Epstein LG, DiCarlo FJ, Joshi VV, Connor EM, Oleske JM, Kay D, et al: Primary lymphoma of the central nervous system in children with acquired immunodeficiency syndrome. Pediatrics 82:355-363, 1988

28. Fallo A, De Matteo E, Preciado MV, Cerqueiro MC, Escoms S, Chabay P, et al: Epstein-Barr virus associated with primary CNS lymphoma and disseminated BCG infection in a child with AIDS. Int J Infect Dis 9:96-103, 2005

29. Felice MS, Zubizarreta PA, Rossi JG, Rose A, Alfaro EM, Sackmann-Muriel F: Diagnosis and successful treatment of childhood primary leptomeningeal lymphoma. Med Pediatr Oncol 34:361-363, 2000

30. Ferreri A, Abrey LE, Blay JV, Borisch B, Hochman J, Neuwelt EA, et al: Summary statement on primary central nervous system lymphomas from the Eighth International Conference on Malignant Lymphoma, Lugano, Switzerland, June 12 to 15 , 2002. J Clin Oncol 21:2407-2414, 2003

31. Ferreri AJ, Reni M, Pasini F, Calderoni A, Tirelli U, Pivnik A, et al: A multicenter study of treatment of primary CNS lymphoma. Neurology 58:1513-1520, 2002

32. Ferreri AJ, Reni M, Villa E: Therapeutic management of primary central nervous system lymphoma: lessons from prospective trials. Ann Oncol 11:927-937, 2000

33. Fliessbach K, Helmstedter C, Urbach H, Althaus A, Pels H, Linnebank M, et al: Neuropsychological outcome after chemotherapy for primary CNS lymphoma. A prospective study. Neurology 64:1184-1188, 2005

34. Freilich RJ, Delattre J, Monjour A, DeAngelis LM: Chemotherapy without radiation therapy as initial treatment for primary CNS lymphoma in older patients. Neurology 46: 435-439, 1996

35. George DH, Scheithauer BW, Aker FV, Kurtin PJ, Burger PC, Cameselle-Teijeiro J, et al: Primary anaplastic large cell lymphoma of the central nervous system: prognostic effect of ALK-1 expression. Am J Surg Pathol 27:487-493, 2003

36. Goldman SC, Gerrard M, Sposto R, Auperin A, Pinkerton R, Michon J, et al: Deletion of cranial irradiation and addition of systemic high dose methotrexate and intrathecal chemotherapy results in 70\% 4-yr. EFS in children and adolescents with central nervous system positive $(\mathrm{CNS}+)$ B-NHL: results of International FAB/LMB 96 study, abstract 5, in Abstracts of the Second International Symposium on Childhood, Adolescent And Young Adult Non-Hodgkin Lymphoma, New York, May 18-20, 2006. Hoboken, NJ: Wiley InterScience, 2006, p 835.

37. Goldstein J, Dickson DW, Rubenstein A, Woods W, Mincer F, Belman AL, et al: Primary central nervous system lymphoma in a pediatric patient with acquired immunodeficiency syndrome. Cancer 66:2503-2508, 1990

38. Haldorsen IS, Aarseth JH, Hollender A, Larsen JL, Espeland A, Mella O: Incidence, clinical features, treatment and outcome of primary central nervous system lymphoma in Norway. A tenyear national survey. Acta Oncol 43:520-529, 2004

39. Herrlinger U, Schabet M, Bitzer M, Petersen D, Krauseneck P: Primary central nervous system lymphoma: from clinical presentation to diagnosis. J Neurooncol 43:219-26, 1999

40. Kadan-Lottic NS, Skluzacek MC, Gurney JG: Decreasing incidence rates of primary central nervous system lymphoma. Cancer 95:193-202, 2002

41. Kai Y, Kuratsu J, Ushio Y: Primary malignant lymphoma of the brain in childhood. Case report. Neurol Med Chir (Tokyo) 8: 232-237, 1998

42. Katz BZ, Andiman WA, Eastman R, Martin K, Miller G: Infection with two genotypes of Epstein-Barr virus in an infant with AIDS and lymphoma of the central nervous system. J Infect Dis 153:601-604, 1986

43. Khan RB, Shi W, Thaler HT, DeAngelis LM, Abrey LE: Is intrathecal methotrexate necessary in the treatment of primary CNS lymphoma? J Neurooncol 58:175-178, 2002

44. Kim HJ, Ha CK, Jeon BS: Primary leptomeningeal lymphoma with long-term survival: a case report. J Neurooncol 48:47-49, 2000

45. Kraemer DF, Fortin D, Doolittle ND, Neuwelt EA: Association of total dose intensity of chemotherapy in primary central nervous system lymphoma (human non-acquired immunodeficiency syndrome) and survival. Neurosurgery 48:1033-1041, 2001

46. Lachance DH, Brizel DM, Gockerman JP, Halperin EC, Burger PC, Boyko OB, et al: Cyclophosphamide, doxorubicin, vincristine, and prednisone for primary central nervous system lymphoma: short-duration response and multifocal intracerebral recurrence preceding radiotherapy. Neurology 44: 1721-1727, 1994

47. Lachance DH, O'Neill BP, Macdonald DR, Jaeckle KA, Witzig TE, Li CY, et al: Primary leptomeningeal lymphoma: report of 9 cases, diagnosis with immunocytochemical analysis, and review of the literature. Neurology 41:95-100, 1991

48. Loning L, Zimmermann M, Reiter A, Kaatsch P, Henze G, Riehm H, et al: Secondary neoplasms subsequent to BerlinFrankfurt-Munster therapy of acute lymphoblastic leukemia in childhood: significantly lower risk without cranial radiotherapy. Blood 95:2770-2775, 2000

49. McAllister LD, Doolittle ND, Guastadisegni PE, Kraemer DF, Lacy CA, Crossen JR, et al: Cognitive outcomes and long-term follow-up results after enhanced chemotherapy delivery for primary central nervous system lymphoma. Neurosurgery 46:51-60, 2000

50. Mead GM, Bleehen NM, Gregor A, Bullimore J, Shirley D, Rampling RP, et al: A medical research council randomized trial in patients with primary cerebral non-Hodgkin lymphoma: cerebral radiotherapy with and without cyclophosphamide, doxorubicin, vincristine, and prednisone chemotherapy. Cancer 89: 1359-1369, 2000

51. Murray K, Kun L, Cox J: Primary malignant lymphoma of the central nervous system. Results of treatment of 11 cases and review of the literature. J Neurosurg 65:600-607, 1986

52. Nelson DF: Radiotherapy in the treatment of primary central nervous system lymphoma (PCNSL). J Neurooncol 43: 241-247, 1999

53. Nelson DF, Martz KL, Bonner H, Nelson JS, Newall J, Kerman $\mathrm{HD}$, et al: Non-Hodgkin's lymphoma of the brain: can high dose, large volume radiation therapy improve survival? Report on a prospective trial by the Radiation Therapy Oncology Group (RTOG): RTOG 8315. Int J Radiat Oncol Biol Phys 23:9-17, 1992

54. Neuwelt EA, Goldman DL, Dahlborg SA, Crossen J, Ramsey F, Roman-Goldstein S, et al: Primary CNS lymphoma treated with osmotic blood-brain barrier disruption: prolonged survival and preservation of cognitive function. J Clin Oncol 9:1580-1590, 1991

55. Neuwelt EA, Guastadisegni PE, Varallyay P, Doolittle ND: Imaging changes and cognitive outcome in primary CNS lymphoma after enhanced chemotherapy delivery. AJNR Am J Neuroradiol 26:258-265, 2005

56. Newell ME, Hoy JF, Cooper SG, DeGraaff B, Grulich AE, Bryant $\mathrm{M}$, et al: Human immunodeficiency virus-related primary central nervous system lymphoma: Factors influencing survival in 111 patients. Cancer 100:2627-2636, 2004

57. Patte C: Treatment strategies and outcome in childhood B-cell lymphoma, abstract 2, in Abstracts of the Second International Symposium on Childhood, Adolescent And Young Adult Non-Hodgkin Lymphoma, New York, May 18-20, 2006. Hoboken, NJ: Wiley InterScience, 2006, p 834 
58. Patte C, Auperin A, Michon J, Behrendt H, Leverger G, Frappaz D, et al: The Société Française d'Oncologie Pédiatrique LMB89 protocol: highly effective multiagent chemotherapy tailored to the tumor burden and initial response in 561 unselected children with B-cell lymphomas and L3 leukemia. Blood 97:3370-3379, 2001

59. Pels H, Schmidt-Wolf I, Galsmacher A, Schulz H, Engert A, Diehl V, et al: Primary central nervous lymphoma: results of a pilot and phase II study of systemic and intraventricular chemotherapy with deferred radiotherapy. J Clin Oncol 21: 4489-4495, 2003

60. Perkins S: Are pediatric and adult diffuse large B-cell lymphoma the same disease? Abstract 39, in Abstracts of the Second International Symposium on Childhood, Adolescent and Young Adult Non-Hodgkin Lymphoma, New York, May 18-20, 2006. Hoboken, NJ: Wiley InterScience, 2006, p 847

61. Rodriguez M, Delgado P, Petito CK: Epstein-Barr virus-associated primary central nervous system lymphoma in a child with the acquired immunodeficiency syndrome. Arch Pathol Lab Med 121:1287-1291, 1997

61. Said JA, Waters BG, Cousens P, Stevens MM: Neuropsychological sequelae of central nervous system prophylaxis in survivors of childhood acute lymphoblastic leukemia. J Consult Clin Psychol 57:251-256, 1989

63. Sandor V, Stark-Vancs V, Pearson D, Nussenblat R, Whitcup SM, Brouwers P, et al: Phase II trial of chemotherapy alone for primary CNS and intraocular lymphoma. J Clin Oncol 16: 3000-3006, 1998

64. Schabet M: Epidemiology of primary CNS lymphoma. J Neurooncol 43:199-201, 1999

65. Schulman H, Hertzanu Y, Maor E, Hadar A: Primary lymphoma of brain in childhood. Pediatr Radiol 21:434-435, 1991

66. Schultz C, Scott C, Sherman W, Donahue B, Fields J, Murray $\mathrm{K}$, et al: Preirradiation chemotherapy with cyclophosphamide, doxorubicin, vincristine, and dexamethasone for primary CNS lymphomas: initial report of Radiation Therapy Oncology Group protocol 88-06. J Clin Oncol 14:556-564, 1996

67. Shehu BB: Primary central nervous system Burkitt's lymphoma presenting with proptosis. Ann Trop Pediatr 23:319-320, 2003

68. Shibamoto Y, Tsutsui K, Dodo Y, Yamabe H, Shima N, Abe M: Improved survival rate in primary intracranial lymphoma treated by high-dose radiation and systemic vincristine-doxorubicin-cyclophosphamide-prednisolone chemotherapy. Cancer 65:1907-1912, 1990

69. Shiozawa Y, Kiyokawa N, Fujimura J, Suzuki K, Yarita Y, Fujimoto J, et al: Primary malignant lymphoma of the central nervous system in an immunocompetent child. A case report. J Pediatr Hematol Oncol 27:561-564, 2005

70. Silfen ME, Garvin JH, Hays AP, Starkman HS, Aranoff GS, Levine LS, et al: Primary central nervous system lymphoma in childhood presenting as progressive panhypopituitarism. J Pediatr Hematol Oncol 23:130-133, 2001

71. Slevin ML, Piall EM, Aherne GW, Johnston A, Lister TA: The pharmacokinetics of cytosine arabinoside in the plasma and cerebrospinal fluid during conventional and high-dose therapy. Med Pediatr Oncol 10 (1 Suppl):157-168, 1982

72. Soussain C, Suzan F, Hoang-Xuan K, Cassoux N, Levy V, Azar $\mathrm{N}$, et al: Results of intensive chemotherapy followed by hematopoietic stem-cell rescue in 22 patients with refractory or recurrent primary CNS lymphoma or intraocular lymphoma. J Clin Oncol 19:742-749, 2001

73. Stewart DJ, Russell N, Atack EA, Quarrington A, Stolbach L: Cyclophosphamide, doxorubicin, vincristine and dexamethasone in primary lymphoma of the brain: a case report. Cancer Treat Rep 67:287-291, 1983

74. Surawicz TS, McArthy BJ, Kupelian V, Jukich PJ, Bruner JM, David FG: Descriptive epidemiology of primary brain and CNS tumors: results from the Central Brain Tumor Registry of the United States, 1990-1994. Neuro-oncol 1:14-25, 1999

75. Taga T, Sakaue Y, Anzai Y, Takeuchi Y, Ohta S: Pediatric primary leptomeningeal lymphoma treated without cranial radiotherapy. Pediatr Blood Cancer 2006. (epub ahead of print)

76. Tomlinson FH, Kurtin PJ, SumanVJ, Scheithauer BW, O'Fallon JR, Kelly PJ, et al: Primary intracerebral malignant lymphoma: a clinicopathological study of 89 patients. J Neurosurg 82:558-566, 1995

77. Torres CF, Korones DN, Powers JM, Vadasz AG: Primary leptomeningeal histiocytic lymphoma in a young child. Med Pediatr Oncol 27:547-550, 1996

78. Uetsuka S, Kajiwara K, Suehiro E, Nishizaki T, Ito H, Kawasaki $\mathrm{K}$ : $\mathrm{T}$ cell malignant lymphoma in the central nervous system after acute lymphoblastic leukemia in a child. Childs Nerv Syst 15:486-489, 1999

79. Uhlenberg B, Reich S, Varnholt V, van Landeghem F, Scheer I, Berdel D, et al: Atypical manifestation of childhood primary cerebral lymphoma restricted to the leptomeninges. Eur J Pediatr 164:653-654, 2005

80. Watanabe T, Katayama Y, Yoshino A, Komine C, Yokoyama T, Fukushima T: Long-term remission of primary central nervous system lymphoma by intensified methotrexate chemotherapy. J Neurooncol 63:87-95, 2003

81. Wynn R, Arkwright PD, Haque T, Gharib MI, Wilkie G, Morton-Jones M, et al: Treatment of Epstein-Barr-virus-associated primary CNS B-cell lymphoma with allogeneic T-cell immunotherapy and stem-cell tranplantation. Lancet Oncol 6:344-346, 2005

82. Yang CP, Wan YL, Hung IJ: Successfully treated central nervous system Burkitt's lymphoma with minimal extraneural disease in a child. J Formos Med Assoc 98:66-69, 1999

Received August 15, 2006.

Received in final form September 13, 2006.

Address reprint requests to: Oussama Abla, M.D., Division of Hematology/Oncology, The Hospital for Sick Children and Department of Paediatrics, University of Toronto, 555 University Ave- 